\title{
Front Matter: Volume 6595
}

, "Front Matter: Volume 6595," Proc. SPIE 6595, Fundamental Problems of Optoelectronics and Microelectronics III, 659501 (6 April 2007); doi: $10.1117 / 12.726858$

SPIE Event: Fundamental Problems of Optoelectronics and Microelectronics III, SPIE. 2006, Harbin, China 


\title{
PROCEEDINGS OF SPIE
}

\section{Fundamental Problems of Optoelectronics and Microelectronics III}

\author{
Yuri N. Kulchin \\ Jinping Ou \\ Oleg B. Vitrik \\ Zhi Zhou \\ Editors
}

12-14 September 2006

Harbin, China

Sponsored by

SPIE Russia Chapter

Russian Foundation for Basic Research

Published by

SPIE-The International Society for Optical Engineering

Volume 6595

Part One of Two Parts

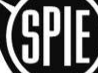

The International Society for Optical Engineering

Proceedings of SPIE-The International Society for Optical Engineering, 9780819467270, v. 6595

SPIE is an international technical society dedicated to advancing engineering and scientific applications of optical, photonic, imaging, electronic, and optoelectronic technologies. 
The papers included in this volume were part of the technical conference cited on the cover and title page. Papers were selected and subject to review by the editors and conference program committee. Some conference presentations may not be available for publication. The papers published in these proceedings reflect the work and thoughts of the authors and are published herein as submitted. The publisher is not responsible for the validity of the information or for any outcomes resulting from reliance thereon.

Please use the following format to cite material from this book:

Author(s), "Title of Paper," in Fundamental Problems of Optoelectronics and Microelectronics III, edited by Yuri N. Kulchin, Jinping Ou, Oleg B. Vitrik, Zhi Zhou, Proceedings of SPIE Vol. 6595 (SPIE, Bellingham, WA, 2007) Article CID Number.

ISSN 0277-786X

ISBN 9780819467270

Published by

SPIE-The International Society for Optical Engineering

P.O. Box 10, Bellingham, Washington 98227-0010 USA

Telephone 1 360/676-3290 (Pacific Time) · Fax 1 360/647-1445

http://www.spie.org

Copyright (C) 2007, The Society of Photo-Optical Instrumentation Engineers

Copying of material in this book for internal or personal use, or for the internal or personal use of specific clients, beyond the fair use provisions granted by the U.S. Copyright Law is authorized by SPIE subject to payment of copying fees. The Transactional Reporting Service base fee for this volume is $\$ 18.00$ per article (or portion thereof), which should be paid directly to the Copyright Clearance Center (CCC), 222 Rosewood Drive, Danvers, MA 01923. Payment may also be made electronically through CCC Online at http://www.copyright.com. Other copying for republication, resale, advertising or promotion, or any form of systematic or multiple reproduction of any material in this book is prohibited except with permission in writing from the publisher. The CCC fee code is 0277-786X/07/ \$18.00.

Printed in the United States of America. 


\section{Contents}

xvii Conference Committees

xix Introduction

\section{Part One}

\section{KEYNOTE PAPERS}

659502 Quantum electronics 50th jubilee (Keynote Paper) [6595-95]

O. N. Krokhin, P.N. Lebedev Physical Institute (Russia)

659503 Optic fiber Bragg grating based sensing technologies and their applications in structural health monitoring (Keynote Paper) [6595-164]

J. Ou, Harbin Institute of Technology (China) and Dalian Univ. of Technology (China);

Z. Zhou, Harbin Institute of Technology (China)

\section{SESSION 1 INTERACTION OF LASER RADIATION WITH MATTER AND NONLINEAR OPTICS}

659504 Influence of energy-transfer up-conversion on diode-end-pumped Q-switched Tm,Ho:YLF lasers [6595-01]

$X$. Zhang, Harbin Engineering Univ. (China) and Harbin Institute of Technology (China);

J. Cui, L. Li, S. YU, Harbin Engineering Univ. (China); Y. JU, Y. Wang, Harbin Institute of Technology (China)

659505 Evaluation and testing of semiconductor laser reliability in optic system [6595-02]

W. Tang, X. Fan, H. Sun, Harbin Institute of Technology (China)

659506 Temporal characteristics of output pulses in Brillouin fiber-optical ring laser [6595-03]

Y. Lü, X. Chong, L. He, Harbin Engineering Univ. (China) and Harbin Institute of Science and Technology (China)

Pagination: Proceedings of SPIE follow an e-First publication model, with papers published first online and then in print and on CD-ROM. Papers are published as they are submitted and meet publication criteria. A unique, consistent, permanent citation identifier (CID) number is assigned to each article at the time of the first publication. Utilization of CIDs allows articles to be fully citable as soon they are published online, and connects the same identifier to all online, print, and electronic versions of the publication.

SPIE uses a six-digit CID article numbering system in which:

- The first four digits correspond to the SPIE volume number.

- The last two digits indicate publication order within the volume using a Base 36 numbering system employing both numerals and letters. These two-number sets start with 00, 01, 02, 03, 04, 05, 06, 07, 08, 09, 0A, OB ... 0Z, followed by 10-1Z, 20-2Z, etc.

The CID number appears on each page of the manuscript. The complete citation is used on the first page, and an abbreviated version on subsequent pages. 
659507 Theoretical study of transient thermal nonlinear refraction induced by nonlinear optical absorption [6595-04]

W. Jiao, X. Zhang, Y. Wang, Y. Song, Harbin Institute of Technology (China)

659508 Third-order nonlinear optical properties and optical limiting property of metallonaphthalocyanine [6595-05]

C. He, Heilongjiang Univ. (China) and Harbin Institute of Technology (China); W. Duan,

Y. Wu, Heilongjiang Univ. (China); Y. Wang, X. Zhang, Y. Song, Harbin Institute of

Technology (China)

659509 Nonlinear errors of passive homodyne polarized laser interferometer [6595-06]

J. Yang, B. Wu, Z. Liu, L. Yuan, Harbin Engineering Univ. (China)

65950A Interaction of partially coherent laser radiation with matter [6595-07]

A. N. Starodub, S. I. Fedotov, A. A. Kozhevnikova, B. V. Kruglov, S. V. Mal'kova, M. V. Osipov, V. N. Puzyrev, A. T. Sahakyan, B. L. Vasin, O. F. Yakushev, P.N. Lebedev Physical Institute (Russia)

65950B Resonator-enhanced low-power all-optical switch with a nonlinear ratio-variable coupler [6595-08]

L. Li, Harbin Engineering Univ. (China) and Harbin Institute of Technology (China); J. Li, Harbin Institute of Technology (China); X. Zhang, Harbin Engineering Univ. (China); L. Chen, Harbin Institute of Technology (China)

65950C Large aperture nonlinear elements from KDP and DKDP crystals: making and using [6595-09]

A. A. Babin, Institute of Applied Physics (Russia)

65950D Realizing all-optical full-adder logic operation with photorefractive crystal phase conjugation [6595-10]

X. Fan, College of Second Aviation (China); G. Lv, Z. Jiang, H. Wang, Y. Yu, Heilongjiang Univ. (China)

65950E Conoscopic methods of optic crystal research [6595-96]

A. V. Syuy, V. I. Stroganov, V. V. Krishtop, Far Eastern State Transport Univ. (Russia);

V. V. Lihtin, Komsomolsk-on-Amur State Technical Univ. (Russia)

$65950 \mathrm{~F}$ Distribution of light pulses from several oscillations in an untuned nonlinear medium [6595-148]

M. I. Voitjk, G. V. Kostina, A. I. Livashvili, Far Eastern State Transport Univ. (Russia)

$65950 \mathrm{G}$ Experimental and theoretical research of propagation of the double-circle laser beam in Kerr-medium [6595-97]

C. Shen, F. Chen, China Jiliang Univ. (China); B. Yin, R. Miao, Shanxi Normal Univ. (China)

$65950 \mathrm{H}$ Optimization of discharge circuit of the TEA $\mathrm{CO}_{2}$ laser with two discharge channels [6595-149]

X. Y. Hu, L. Zhang, D. Ren, Y. Qu, W. Zhao, B. Song, Harbin Institute of Technology (China)

65950I A novel all-fiber self-organization coherent erbium-doped fiber laser [6595-98] X. J. Jia, F. N. Liu, S. G. Fu, J. Zhang, Y. G. Liu, Z. C. Guo, S. Z. Yuan, G. Y. Kai, X. Y. Dong, Institute of Modern Optics, Nankai Univ. (China) 
65950J Analytical descriptions of damage threshold of dielectric materials irradiated by femtosecond pulses [6595-99]

G. Zhao, Q. Hao, W. Qi, J. Chen, J. Zhang, Sichuan Univ. (China)

65950K Thermal behavior of thin metal films irradiated by ultra-short pulse laser [6595-100]

Q. Hao, G. Zhao, W. Qi, Sichuan Univ. (China)

65950L An improvement on the $4 \mathrm{f}$ coherent imaging system for measuring the nonlinear refraction [6595-150]

Y. Li, X. Zhang, Harbin Institute of Technology (China); Y. Wang, Suzhou Univ. (China);

Y. Song, Harbin Institute of Technology (China)

$65950 \mathrm{M}$ Laser generation and reception of acoustic ultrasonic waves in solids [6595-151]

V. I. Arkhipov, P. V. Bazylev, V. A. Lugovoy, Dalstandart, RSRI (Russia)

65950N Hologram image storage in the methyl-red doped nematic liquid crystal films [6595-101]

K. Gu, H. Gao, D. Gong, Z. Zhou, Harbin Institute of Technology (China)

659500 Influence of the Mollow triplet on the spectrum of the scattered radiation by a multiatom system [6595-152]

B. B. Averbukh, Tihooceansky State Univ. (Russia)

SESSION 2 MICROELECTRONIC AND NANOELECTRONIC STRUCTURES FOR OPTOELECTRONICS

65950P Effect of In ions on photorefractive properties in Fe:In:LiNbO 3 crystals [6595-11]

T. Zhang, T. Geng, W.-M. Sun, Harbin Engineering Univ. (China)

65950Q Transmission characteristic of photonic crystals coupler [6595-12]

C. Guan, D. Xie, L. Yuan, Harbin Engineering Univ. (China)

65950R Experimental study on femtosecond laser micromaching of grooves in spring steel [6595-13]

L. Qi, X. Wu, Y. Wang, Harbin Institute of Technology (China)

$65950 \mathrm{~S}$ Formation of azimuthally and radially polarized Bessel light beams in one-dimensional photonic crystals having photorefractive properties [6595-14]

S. Kurilkina, V. Belyi, N. Kazak, Institute of Physics (Belarus); S. Shandarov, Tomsk State Univ. of Control Systems and Radioelectronics (Russia); P. Ropot, Institute of Physics (Belarus)

$65950 \mathrm{~T}$ Nanosecond reverse saturable absorption in metal cluster cis-Cp* $\left.{ }_{2} \mathrm{Mo}_{2} \mathrm{~S}_{4} \mathrm{Cu}_{2} \mathrm{I}_{2} \mathrm{CC}_{\mathrm{CH}_{2}} \mathrm{Cl}_{2}\right)_{2}$ solution [6595-15]

J. Yang, J. Gu, Suzhou Univ. (China); G. Shi, Y. Li, Harbin Institute of Technology (China);

Y. Song, Z. Ren, J. Lang, Suzhou Univ. (China)

$65950 \mathrm{~S}$ Study on trap states in polyvinylcarbazole by thermally stimulated current spectrum [6595-16]

L. He, X. Wang, W. Zhang, X. Wang, Harbin Univ. of Science and Technology (China)

65950V Temperature influence on all-optical poling of glasses [6595-17]

V. A. Smirnov, L. I. Vostrikova, I. A. Ishimov, Institute of Semiconductor Physics (Russia) 
65950W Study on holographic image storage and reconstruction in azo-dye-doped liquid-crystal films [6595-18]

H. Gao, Z. Zhou, Harbin Institute of Technology (China)

65950X New self-developed holographic media-dichromated gelatin with isopropanol [6595-19] A. N. Malov, A. V. Neupokoeva, Irkutsk Higher Military Aviation Engineer School (Russia)

65950Y Temperature dependences of optical absorption and its light-induced changes in sillenite crystals [6595-20]

S. M. Shandarov, L. E. Polyakova, A. E. Mandel, M. G. Kisteneva, J. Vidal, Tomsk State Univ. of Control Systems and Radioelectronics (Russia); YU. F. Kargin, A. V. Egorysheva, N.S.

Kurnakov Institute of General and Inorganic Chemistry (Russia)

$65950 \mathrm{Z}$ The influence of forms and sizes of heterogeneous systems on the band bending in $\mathrm{AgBr}$ Agl [6595-21]

A. V. Khaneft, A. S. Poplavnoi, B. A. Sechkarev, L. V. Sotnikova, Kemerovo State Univ. (Russia)

659510 A new type of dynamic infrared image modulator based on the MEMS technique [6595-22] F. Sun, C. Li, Harbin Institute of Technology (China); W. Jiang, S. Zhang, D. Wu, Y. Shi, Heilongjiang Bada Universal Semiconductor Inc. (China)

659511 Electro-mechanical properties of carbon black filled EP/PI conductive films [6595-23] X. Ji, H. Li, J. Ou, Harbin Institute of Technology (China)

659512 Atomic motion in the thermal field of dissipative matter near the surface of material [6595-102]

B. B. Averbukh, I. B. Averbukh, Tihooceansky State Univ. (Russia)

659513 Microring resonator-coupled Mach-Zehnder interferometer as trigger pulse generator, optical differentiator, and integrator [6595-103]

L. Li, Harbin Engineering Univ. (China) and Harbin Institute of Technology (China); X. Zhang,

P. Sun, Harbin Engineering Univ. (China); L. Chen, Harbin Institute of Technology (China)

659514 Influence of composition ratio on the nonlinear optical properties of $A g G a_{1-x} \ln _{x} S_{2}$ and $\mathrm{Hg}_{1-x} \mathrm{Cd}_{\mathbf{x}} \mathrm{Ga}_{2} \mathrm{~S}_{4}$ [6595-104]

G. Ji, T. Shen, J. Huang, B. Zhao, Harbin Univ. of Science and Technology (China);

Yu. M. Andreev, Institute for Monitoring of Climatic and Ecological Systems (Russia);

V. V. Atuchin, Institute of Semiconductor Physics (Russia); G. Lanskiy, Institute for Monitoring of Climatic and Ecological Systems (Russia)

659515 Waveguiding in air with left-handed material [6595-105]

D. Xie, C. Guan, L. Yuan, Harbin Engineering Univ. (China)

659516 Optical limiting properties and nonlinearity of a novel cubane-like shaped Mo/S/Cu cluster polymer [6595-106]

J. Xu, N. Liu, J. Fang, Y. Song, J. Lang, J. Yang, Z. Ren, Suzhou Univ. (China)

659517 Pulse LDA-pumped passively Q-switched mode locked Nd:YVO4 laser with a GaAs saturable absorber [6595-153]

X. Liu, R. Fu, Institute of Modern Optics, Nankai Univ. (China) 
659518 Research of photoprocesses in compositions of the polymer-semiconductor [6595-154] D. S. Shtarev, I. Ju. Prosanov, Far Eastern State Univ. of Means of Communication (Russia); A. A. Tsiganenko, St. Petersburg State Univ. (Russia)

659519 Highly birefringent index-guiding photonic crystal fibers with two big circular holes in elliptical-air-hole cladding [6595-107]

Y. Yue, G. Kai, Z. Wang, L. Jin, T. Sun, Y. Lu, C. Zhang, Y. Li, J. Liu, Y. Liu, S. Yuan, X. Dong, Institute of Modern Optics, Nankai Univ. (China)

65951 A Polarization characteristics of the large-mode-area fiber amplifier applied in coherent combination [6595-108]

Z. Guo, Institute of Modern Optics, Nankai Univ. (China) and Inner Mongolia Normal Univ. (China); S. Fu, Y. Liu, X. Jia, L. Si, Y. Jin, S. Yuan, X. Dong, Institute of Modern Optics, Nankai Univ. (China)

65951B Goos-Hänchen shift in anisotropic left-handed materials [6595-109]

Y. Jiang, Y. Zhang, Y. Fu, C. Hou, Z. Zhou, X. Sun, Harbin Institute of Technology (China)

65951C Cumulative UV-monitoring using chemically modified ZnO or TiOn layers [6595-110] I. Prosanov, Far Eastern Transport Univ. (Russia); P. Bogdanoff, S. Fiechter, H. Tributsch, HahnMeitner-Institut (Germany)

\section{SESSION 3 COHERENT OPTICS AND OPTIC METHODS FOR MEASUREMENT AND INFORMATION} PROCESSING

$65951 \mathrm{D}$ Algorithm study of phase diverse speckle corrective technique [6595-24] A. Zhang, T. Wang, Z. Li, J. Zhang, B. Liang, Harbin Institute of Technology (China)

65951E Successive elimination motion estimation algorithm based on multi-resolution [6595-25] B. Zhang, Y. Zhao, Z. Zhong, Harbin Institute of Technology (China)

$65951 \mathrm{~F} \quad$ Recording of incoherent reflective volume Fourier holograms for optical correlators [6595-26]

V. G. Rodin, S. N. Starikov, Moscow Engineering Physics Institute (Russia)

$65951 \mathrm{G}$ Study on memories of temporal lobes and the principles of lateralization using near infrared spectroscopy [6595-27]

K. Kamakura, Kokushikan Univ. (Japan)

$65951 \mathrm{H} \quad$ Detection algorithm for space dim moving object [6595-28]

H.-B. Pan, W. Zhang, M.-Y. Cong, Harbin Institute of Technology (China)

659511 Estimation and optical diagnostics of combustion with high temperature air [6595-29] K. Kishimoto, Kokushikan Univ. (Japan)

$65951 \mathrm{~J}$ Simulation and experimental research on spherical dome by 3D laser-forming of square feet [6595-30]

L. Yang, Y. Wang, Harbin Institute of Technology (China)

65951K ICF laser target alignment sensor calibration system [6595-31]

L. Bao, Z. Zhang, G. Liu, B. Liu, Z. Pu, Harbin Institute of Technology (China) 
$65951 \mathrm{~L}$ Correlation method of processing single fiber multimode interferometer (SFMI) signals using a charge coupled device [6595-32]

Yu. N. Kulchin, O. B. Vitrik, A. D. Lantsov, Institute for Automation and Control Processes (Russia)

$65951 \mathrm{M}$ Example of using small falling weight deflectomer (FWD) for Earth structures and low cost road pavement in Japan [6595-33]

H. Shibata, Y. Tanaka, I. Ono, Kokushikan Univ. (Japan); T. Okano, Tokyosokkikenkyujo Co., Ltd. (Japan)

$65951 \mathrm{~N}$ Application of modified Kohnen's network to optimization problems [6595-34]

T. Shimizu, Kokushikan Univ. (Japan)

659510 The application of data fusion in optical theodolite coordinate measurement system [6595-35]

Z. Tong, W. Tang, Harbin Institute of Technology (China)

$65951 P \quad$ A novel ultrasonic phased array inspection system to NDT for offshore platform structures [6595-36]

H. Wang, B. Shan, X. Wang, J. Ou, Harbin Institute of Technology (China)

$65951 Q \quad$ LPCC invariant correlation filters: variants of application [6595-37]

S. Yu. Shelestov, Moscow Academy of Employment Market and Information Technologies (Russia); A. V. Shevchuk, S. I. Sirotkin, R. S. Starikov, Moscow Engineering Physics Institute (Russia)

65951R Optoelectronic vector-matrix processors: technical limitations [6595-38]

R. S. Starikov, Moscow Engineering Physics Institute (Russia)

659515 Analysis of the nonlinear mechanisms of light absorption in transparent materials under the ultrashort pulse laser action [6595-39]

I. N. Zavestovskaya, P.N. Lebedev Physical Institute (Russia); P. G. Eliseev, P.N. Lebedev Physical Institute (Russia) and Ctr. for High Technology Materials, Univ. of New Mexico (USA); O. N. Krokhin, P.N. Lebedev Physical Institute (Russia)

$65951 \mathrm{C}$ Computer holography by means of the laser diodes [6595-40]

A. N. Borodin, Irkutsk Air Force Engineering Higher School, Military Institute (Russia);

V. V. Ilchenko, Technical Univ. of Munich (Germany); A. N. Malov, A. V. Sychevskiy, Irkutsk Air Force Engineering Higher School, Military Institute (Russia)

$65951 \mathrm{U}$ Image segmentation algorithms using the model of the system with abruptly changing random structure [6595-41]

A. N. Malov, B. M. Mironov, Irkutsk Air Force Engineering Higher School, Military Institute (Russia)

$65951 \mathrm{~V}$ Digital Foucault knife as a phase manipulation in the Walsh-Hadamard image transformations [6595-42]

A. V. Bronnikov, A. N. Malov, A. N. Onackiy, Irkutsk Air Force Engineering Higher School, Military Institute (Russia) 
$65951 \mathrm{~W}$ Experimental modeling of high accuracy measurement of circular and radial harmonics [6595-43]

N. N. Evtikhiev, S. N. Litovchenko, A. V. Shevchuk, R. S. Starikov, E. Yu. Zlokazov, Moscow Engineering Physics Institute (Russia)

65951X Research on frame capture of high speed and image storage [6595-44]

D. Hao, H. Ju, Harbin Institute of Technology (China)

$65951 Y$ Development of automated inspection system for highway surface distress [6595-45]

X. Hou, H. Wang, Q. Wang, Z. Wang, Harbin Institute of Technology (China)

659512 Adaptive photodetectors for vibration monitoring [6595-46]

I. A. Sokolov, M. A. Bryushinin, V. V. Kulikov, A.F. Ioffe Physico-Technical Institute (Russia);

K. T. V. Grattan, City Univ. (United Kingdom); A. S. Abyzov, A. V. Rybka, L. N. Davydov,

$\vee$. V. Slezov, Kharkov Institute of Physics and Technology (Ukraine)

659520 The analysis of the thermal effects arising at interaction of laser radiation with the multilayered biomaterial by using Monte Carlo method [6595-47]

A. Yu. Setejkin, I. V. Krasnikov, Amur State Univ. (Russia)

659521 A study on building a wireless acceleration sensor network for global monitoring on the cable-stayed bridge of Songhua River [6595-48]

Y. Yu, Harbin Institute of Technology (China) and Tsinghua Unigroup Ltd. (China); J. Ou, Harbin Institute of Technology (China)

659522 The application of ultrasonic phased array system to the inspection of fillet weld of flat plate [6595-49]

B. Shan, H. Wang, X. Wang, Z. Duan, Harbin Institute of Technology (China); J. Ou, Harbin Institute of Technology (China) and Dalian Univ. of Technology (China)

659523 A star tracking algorithm suitable for star sensor [6595-50]

B. Li, Y. Zhang, H. Li, C. Wang, Harbin Institute of Technology (China)

659524 The backscattering property experiment research of wake bubbles [6595-111]

L. Su, W. Zhang, D. Ren, X. Hu, Harbin Institute of Technology (China)

659525 Experimental research on water-jet guided laser processing [6595-112]

L. Li, Y. Wang, L. Yang, J. Chu, Harbin Institute of Technology (China)

659526 Theoretical analysis of multiprobe confocal 3D detection system [6595-113]

H. Li, Z. Pu, Harbin Institute of Technology (China)

659527 Approach to retina optical coherence tomography image processing [6595-114] J. Yuan, Harbin Engineering Univ. (China); R. Liu, Eye Hospital, First Affiliated Hospital of Harbin Medical Univ. (China); G. Xuan, Second Affiliated Hospital of Harbin Medical Univ. (China); J. Yang, L. Yuan, Harbin Engineering Univ. (China)

659528 Experimental research on power spectrum processing in joint transform correlator image recognition [6595-155]

W. Sun, Y. Yang, Harbin Engineering Univ. (China)

659529 Grain effect on imaging of spatial optical system [6595-115]

D. Wu, Y. Zhou, S. Guo, Harbin Institute of Technology (China) 
65952A Neural-like optoelectronic processing system [6595-116]

N. A. Rybalchenko, I. V. Denisov, V. A. Sedov, I. K. Vernigora, Maritime State Univ. (Russia)

65952B PZT active health monitoring for fatigue accumulative damage of concrete beam containing nano-particles for pavement [6595-117]

M. Zhang, H. Li, J. Ou, Harbin Institute of Technology (China)

65952C High resolution interrogation technique based on linear photodiode array spectrometer for fiber Bragg grating sensors [6595-118]

S. Zhang, Y. Liu, F. Li, Institute of Semiconductors (China)

65952D Introduction of a four-step modulation used in PGC method [6595-1 19]

Y. Liu, M. Zhang, Y. Liao, Tsinghua Univ. (China)

65952E Analysis and application for a new type of optical fiber interferometer with three-beam system [6595-120]

K. Yin, L. Wang, T. Ding, M. Zhang, Y. Liao, Tsinghua Univ. (China)

65952F Method of surface roughness measurement based on interferometry [6595-121]

X. F. Zhang, Z. P. Wang, Y. E. Zhang, L. H. Wang, Y. M. Zhang, Harbin Engineering Univ. (China)

\section{Part Two}

SESSION 4 OPTICAL FIBER SENSORS AND THEIR APPLICATIONS

$65952 \mathrm{G}$ Stabilized fiber optic sensor for remote measuring angle of inclination [6595-51]

Y. N. Kulchin, O. B. Vitrik, A. V. Dyshlyuk, Institute for Automation and Control Processes (Russia)

$65952 \mathrm{H}$ An optical voltage sensor based on the theory of Fabry-Perot interferometer [6595-52] Y. Liu, H. Zhao, X. Yu, Harbin Univ. of Science and Technology (China)

659521 All-fiber system based on Fabry-Perot sensor for partial discharges in transformer oil [6595-53]

M. Li, H. Zhao, Harbin Univ. of Science and Technology (China)

65952J Study of FBG sensing demodulation in AC voltage sensing with CWDM [6595-54]

J. Zhang, Harbin Univ. of Science and Technology (China) and Harbin Normal Univ. (China); H. Zhao, Y. Xiong, Z. Zhang, Harbin Univ. of Science and Technology (China)

65952K A fiber Bragg grating strain sensor based on ASE light source demodulation technology [6595-55]

Y. Xiong, Harbin Univ. of Science and Technology (China); Z. Yang, Harbin Normal Univ. (China); H. Zhao, Harbin Univ. of Science and Technology (China); J. Zhang, Harbin Normal Univ. (China); M. Xiao, Harbin Univ. of Science and Technology (China)

$65952 \mathrm{~L}$ Fiber Bragg grating sensors array based on optical frequency domain reflectometry technology [6595-56]

Y. Xiong, L. He, T. Chen, X. Wang, W. Yang, Harbin Univ. of Science and Technology (China) 
65952M Temperature-insensitive strain sensor based on the measurement of reflected bandwidth from tapered fiber grating by a scanning FBG [6595-57]

X. Yang, Q. Zhang, Harbin Institute of Technology (China); Y. YU, Jilin Univ. (China); S. Sun, Harbin Institute of Technology (China)

65952N Research on temperature independent FBG obliquity sensor [6595-58]

Y. Cao, X. Ma, W. Fang, Tianjin Univ. of Technology (China); G. Kai, X. Dong, Institute of Modern Optics, Nankai Univ. (China)

659520 Laser interferometer used for nanometer vibration measurements [6595-59]

J. Sun, J. Yang, Z. Liu, L. Yuan, Harbin Engineering Univ. (China)

65952P A portable interrogation system based on the linear InGaAs photodiode array and volume phase grating [6595-60]

G. Li, J. Zhang, B. Liu, S. Yuan, G. Kai, X. Dong, Institute of Modern Optics, Nankai Univ. (China)

65952Q Multiparameters measurement by using a four-core fiber [6595-61]

L. Yuan, X. Wang, Harbin Engineering Univ. (China)

65952R The strain measurement and analysis of fluorescence fiber [6595-62]

H. Jiang, W. Sun, C. Zhang, Z. Liu, F. Jiang, Y. Zhang, Harbin Engineering Univ. (China)

65952S The investigation of liquid analysis method based on fiber micro-drop sensor [6595-63] W. Sun, X. Li, Y. Zeng, Harbin Engineering Univ. (China)

65952T The distributed Brillouin sensor system based on offset locking two DFB lasers [6595-64] Y. Li, X. Bao, L. Zou, F. Ravet, Univ. of Ottawa (Canada)

$65952 \mathrm{U} \quad$ Fiber bragg grating sensors for arch bridge suspender health monitoring [6595-65] D. Li, Z. Zhou, N. Deng, J. Ou, Harbin Institute of Technology (China)

65952V Health diagnosis of arch bridge suspender by acoustic emission technique [6595-66] D. Li, J. Ou, Harbin Institute of Technology (China)

65952W Study on fabrication of smart FRP-OFBG composite laminates and their sensing properties [6595-67]

Y. Wang, Z. Zhou, Harbin Institute of Technology (China); J. Ou, Harbin Institute of Technology (China) and Dalian Univ. of Technology (China)

65952X Liquid refractive index and temperature measurement based on LPFG [6595-68] C. Wang, Z. P. Wang, Harbin Engineering Univ. (China); G. S. Zhang, Harbin Engineering Univ. (China) and Beijing Institute of Graphic Communication (China); R. D. Ma, Y. M. Zhang, Harbin Engineering Univ. (China)

$65952 Y \quad$ FBG bending gauge on bridges: an effort toward standardization of bridge structural health monitoring [6595-69]

I-W. Wu, Prime Optical Fiber Corp. (Taiwan); C.-Y. Wang, M.-H. Chen, H.-L. Wang, National Central Univ. (Taiwan); A. Cheng, P. Tsai, D. Wu, H.-W. ChangChien, H. Shang, Prime Optical Fiber Corp. (Taiwan) 
$65952 Z$ A low cost mutiplexed $1.331 \mu \mathrm{m}$ spectroscopic remote methane sensor system [6595-70] J. Ni, T. Liu, J. Chang, Shandong Academy of Science (China) and Shandong Micro-Sensor Photonics Ltd. (China); Q. Wang, X. Han, Y. Zhang, Shandong Academy of Science (China)

659530 Effect of the dispersion of the reflection-induced retardance upon the sensitivity of an optical current sensor [6595-71]

Z. P. Wang, Y. Qi, X. Y. Liu, Y. M. Zhang, Harbin Engineering Univ. (China)

659531 Effect of the dispersion of Verdet constant upon the sensitivity of an optical current sensor [6595-72]

Z. P. Wang, Y. Qi, X. Y. Liu, Y. M. Zhang, Harbin Engineering Univ. (China)

659532 Research on construction monitoring of the Third Nanjing Yangtze Bridge using FBG sensors [6595-73]

Q. Hu, China Earthquake Administration, Institute of Engineering Mechanics (China) and Harbin Institute of Technology (China); Z. Zhou, Harbin Institute of Technology (China);

J. Ou, Harbin Institute of Technology (China) and Dalian Univ. of Technology (China)

659533 Research and application of highway tunnel fire alarm system based on fiber Bragg grating sensor technology [6595-74]

C. Zhou, L. Chen, D. Jiang, Wuhan Univ. of Technology (China); J. He, S. Zhang, Wuhan

Optic Science and Technology Ltd. Co. (China)

659534 State-of-the-art optical fiber ends: fabrication and application [6595-75]

L. Yuan, Harbin Engineering Univ. (China)

659535 Health monitor on asphalt pavement of highway based on FBG technique [6595-76]

Q. Hu, China Earthquake Administration, Institute of Engineering Mechanics (China) and Harbin Institute of Technology (China); Z. Zhou, H. Li, Harbin Institute of Technology (China); J. Ou, Harbin Institute of Technology (China) and Dalian Univ. Of Technology (China)

659536 Measuring tide and vibration of the submarine and aerial fibers by polarization mode dispersion [6595-78]

X. Bao, Z. Zhang, D. Waddy, L. Chen, Univ. of Ottawa (Canada)

659537 Current situation and prospect of distributed Brillouin sensing technology [6595-79]

J. He, Z. Zhou, Harbin Institute of Technology (China); J. Ou, Harbin Institute of Technology

(China) and Dalian Univ. of Technology (China)

659538 Effects of reciprocal parameters upon a FMOCT [6595-80]

Z. P. Wang, C. Kang, X. Y. Liu, Y. M. Zhang, Harbin Engineering Univ. (China)

659539 Experiment and analysis based on polarization optical time domain reflectometry (POTDR) [6595-81]

Z. Li, C. Wu, Y. Liu, M. Cheng, Y. Wang, C. Tian, Beijing Jiaotong Univ. (China)

65953A A novel electric current sensor based on Fiber Bragg gratings and magnetostrictive composites [6595-82]

X. Dong, X. Guan, Harbin Institute of Technology (China); J. Ou, Harbin Institute of Technology (China) and Dalian Univ. of Technology (China)

65953B Tapered-fiber liquid dropping-speed monitoring sensors [6595-83]

C. Zhang, W. Sun, C. Guo, X. Wang, Harbin Engineering Univ. (China) 
65953C Hybrid optical bistability in fiber Fabry-Perot interferometer by use of a widely wavelengthswept fiber laser [6595-84]

G. Lv, Harbin Institute of Technology (China) and Heilongjiang Univ. (China); J. Ou, Harbin Institute of Technology (China) and Dalian Univ. of Technology (China); Z. Zhou, Harbin Institute of Technology (China); H. Ye, C. Yang, S. Shang, C. Li, Heilongjiang Univ. (China)

65953D The application of optical fiber sensors in the engineering monitoring of Dongying Yellow River Bridge [6595-85]

T. Zhang, Harbin Institute of Technology (China); J. Ou, Harbin Institute of Technology

(China) and Dalian Univ. of Technology (China)

65953E Detection blind area of infrared sensors for moving target detection [6595-86]

K. Li, W. Zhang, C. Wu, Harbin Institute of Technology (China)

65953F A novel design of CCD spectral detection circuit for FBG sensor interrogation [6595-87] S. Gong, Heilongjiang Univ. (China); G. Lv, Heilongjiang Univ. (China) and Harbin Institute of Technology (China); X. Li, X. Jiang, S. Shang, C. Yang, H. Wang, C. Li, Heilongjiang Univ. (China)

65953G FBG sensor interrogation using fiber optical bistability in frequency domain [6595-88] G. Lv, Harbin Institute of Technology (China) and Heilongjiang Univ. (China); J. Ou, Harbin Institute of Technology (China) and Dalian Univ. of Technology (China); H. Ye, Heilongjiang Univ. (China); Z. Zhou, Harbin Institute of Technology (China); S. Shang, C. Yang, H. Wang, Heilongjiang Univ. (China)

$65953 \mathrm{H}$ Design of integrated monitoring system for the Dongying Yellow River Bridge based on optical fiber sensing technique [6595-89]

T. Zhang, Harbin Institute of Technology (China); J. Ou, Harbin Institute of Technology (China) and Dalian Univ. of Technology (China)

659531 Self-sensing concrete-filled FRP tube using FBG strain sensor [6595-90]

X. Yan, H. Li, Harbin Institute of Technology (China)

65953J Traffic-load effects calculation for arch bridge suspenders based on loading effects FBG monitoring system in-service data [6595-91]

X. Gao, D. Li, N. Deng, Harbin Institute of Technology (China); J. Ou, Harbin Institute of Technology (China) and Dalian Univ. of Technology (China)

65953K Study on a new kind of surface sticking strain sensor with sensitivity enhanced based on FBG [6595-92]

J. He, Z. Zhou, H. Dong, G. Zhang, Harbin Institute of Technology (China)

65953L Study on FBG-based sensor for simultaneous dual-measurement of pressure and temperature [6595-93]

Z. Zhou, D. Wang, J. He, J. Ou, Harbin Institute of Technology (China)

65953M Recent advances in fiber-optic F-P interferometric sensors [6595-94]

Y.-J. Rao, Univ. of Electronic Science and Technology of China (China) and Chongqing Univ. (China) 
$65953 \mathrm{~N}$ Analysis and simulation of optical polarization fluctuation of interferometric fiber optic gyroscope [6595-156]

H. Gu, Institute of Modern Optics, Nankai Univ. (China) and Tianjin Navigation Instrument Research Institute (China); G. Yang, Y. Yang, H. Weng, Tianjin Navigation Instrument Research Institute (China); Q. Zhao, Institute of Modern Optics, Nankai Univ. (China)

659530 Study on the demodulation technique of fiber grating sensor arrays based on a tunable pulsed laser [6595-157]

B. Dong, Q. Zhao, Institute of Modern Optics, Nankai Univ. (China); S. He, S. Hu, Beijing Univ. of Technology (China); T. Guo, L. Xue, Institute of Modern Optics, Nankai Univ. (China)

65953P An optical measurement method about line width of pulse laser [6595-158] B. Song, W. Zhao, D. Ren, H. Zhao, S. Mo, Harbin Institute of Technology (China)

65953Q Intensity-referenced and temperature-independent pressure sensing based on strainchirped fiber Bragg grating [6595-122]

T. Guo, Q. Zhao, L. Xue, J. Lv, H. Kang, B. Dong, S. Li, H. Gu, G. Huang, X. Dong, Institute of Modern Optics, Nankai Univ. (China)

65953R Temperatute-independent FBG displacement measurement based on bandwidth modulation and optical power detection [6595-123]

T. Guo, Q. Zhao, H. Kang, J. Lv, L. Xue, S. Li, B. Dong, H. Gu, G. Huang, X. Dong, Institute of Modern Optics, Nankai Univ. (China)

65953S Performance analysis of an in-line optical fiber analysis system for well crude oil [6595-159] D. Meng, H. Xuan, M. Zhang, S. Lai, Y. Liao, Tsinghua Univ. (China)

65953T A distributed temperature-sensing system based on FBG [6595-124]

X. YU, H. Zhao, Y. Liu, Harbin Univ. Of Science and Technology (China)

$65953 \mathrm{U}$ Temperature insensitive wheel-type FBG pressure sensor [6595-125]

J. Luo, B. Liu, G. Kai, S. Yuan, X. Dong, Institute of Modern Optics, Nankai Univ. (China)

65953V Development of the optical instrument transformer for DC voltage measurement [6595-126] P. Zhu, G. Zhang, Tsinghua Univ. (China)

65953W The research of propagation constant in grapefruit microstructure optical fibers with lateral pressure [6595-127]

H. Liu, Institute of Modern Optics, Nankai Univ. (China); W. Zhang, Institute of Modern Optics, Nankai Univ. (China) and Institute of Semiconductors (China); Q. Tu, M. Jiang, Z. Wang, Y. Liu, G. Kai, X. Dong, Institute of Modern Optics, Nankai Univ. (China)

65953X AC current sensing with fiber Bragg grating [6595-128]

H. Zhao, Harbin Univ. of Science and Technology (China); J. Zhang, Harbin Univ. of Science and Technology (China) and Harbin Normal Univ. (China); Y. Xiong, Z. Zhang, Harbin Univ. of Science and Technology (China)

65953Y FBG current sensor based on CWDM demodulation [6595-129]

H. Zhao, Y. Xiong, Harbin Univ. of Science and Technology (China); J. Zhang, Harbin

Normal Univ. (China); H. Zhao, Harbin Univ. of Science and Technology (China)

$65953 Z$ Active sensing of DBR laser with self-mixing interference [6595-130]

J. Zhou, M. Wang, D. Han, Nanjing Normal Univ. (China) 
659540 Speckle feedback-injected erbium-doped fiber ring laser for velocity detecting [6595-160] D. Han, Nanjing Normal Univ. (China) and Nanchang Univ. (China); M. Wang, J. Zhou, Nanjing Normal Univ. (China)

659541 The design and fabrication of an optical fiber MEMS pressure sensor [6595-131] Y. Ge, M. Wang, H. Rong, X. Chen, Nanjing Normal Univ. (China)

659542 Study on the passive-drawn fiber optic liquid analysis technique [6595-132] A. Zhou, J. Sun, L. Yuan, H. Xiao, Harbin Engineering Univ. (China)

659543 A novel fiber optic Fabry-Perot temperature sensor [6595-133] W. Zhang, Shijiazhuang Railway Institute (China) and Institute of Semiconductors (China); B. Sun, J. Dai, Y. Du, Shijiazhuang Railway Institute (China)

659544 Investigation on pressure sensitivity of fiber optic mandrel hydrophone [6595-134] W. Zhang, Y. Liu, F. Li, Institute of Semiconductors (China)

$659545 \quad 800 \mathrm{~nm}$ fiber Bragg grating sensing interrogation system using TFBG and CCD array [6595-135]

B. Liu, Institute of Modern Optics, Nankai Univ. (China); R. Suo, K. Zhou, Aston Univ. (United Kingdom); L. Jin, J. Zhang, Y. Liu, G. Kai, X. Dong, Institute of Modern Optics, Nankai Univ. (China)

659546 A novel fiber-mercury temperature sensor [6595-136] W. Zhang, Shijiazhuang Railway Institute (China) and Institute of Semiconductors (China); J. Dai, B. Sun, Y. Du, Shijiazhuang Railway Institute (China)

659547 Study on the BRDF application [6595-137]

C. Qi, Harbin Engineering Univ. (China) and Harbin Institute of Technology (China);

C. Yang, J. Dai, Harbin Institute of Technology (China); G. Zhao, Harbin Engineering Univ. (China)

659548 Four-core fiber square grid pattern generator [6595-138]

L. Yuan, S. Zhao, W. Xue, Harbin Engineering Univ. (China)

659549 Design of structured light by using three PM fibers for Moiré interferometric profilometry [6595-139]

L. Yuan, Harbin Engineering Univ. (China)

65954A The noise analysis and digital realization of arctangent approach of PGC demodulation for optic interferometric sensors [6595-140]

F. Liao, M. Zhang, L. Wang, Y. Liao, Tsinghua Univ. (China)

65954B Research on an improved passive demodulation method for optical fiber interferometer with $3 \times 3$ coupler [6595-141]

K. Yin, M. Zhang, T. Ding, L. Wang, Y. Liao, Tsinghua Univ. (China)

65954C Fiber optic vibration sensor based on over-coupled fused coupler [6595-142]

J. Chang, Shandong Academy of Science (China) and Shandong Univ. (China); L. Ma, Shandong Micro-Sensor Photonics, Ltd. (China); T. Liu, Shandong Academy of Science (China) and Shandong Micro-Sensor Photonics, Ltd. (China); H. Wang, D. Huo, J. Ni, Z. Shi, Shandong Micro-Sensor Photonics, Ltd. (China) 
65954D Study of multiple record of the optical information on photothermoplastic mediums (PTPM) in the holographic way [6595-143]

T. I. Goglidze, I. V. Dement'ev, Moldavian State Univ. (Moldova); Y. E. Kortiukova,

N. I. Matskova, Dniester State Univ. (Moldova)

65954E Construction of the fiber-optical temperature measuring system [6595-161]

V. A. Sedov, I. V. Denisov, N. A. Rybalchenko, Maritime State Univ. (Russia)

65954F Ternary influences on the fiber-optical measuring network [6595-144]

I. V. Denisov, N. A. Rybalchenko, V. A. Sedov, Maritime State Univ. (Russia)

$65954 \mathrm{G}$ The amplification of stimulated Brillouin scattering in backward pumped $\mathrm{S}$ band distributed fiber Raman amplifier [6595-145]

H. Liu, Z. Zhang, China Jiliang Univ. (China); C. Li, H. XU, China Jiliang Univ. (China) and Univ. of Shanghai for Science and Technology (China); J. Wang, China Jiliang Univ.

(China); I. S. Kim, Korea Electrotechnology Research Institute (South Korea)

65954H Fiber optic four-element hydrophone array [6595-146]

Y. Jiang, Y. Zou, Beijing Institute of Technology (China)

65954I A digital liquid level sensor system based on parallel fiber sensor heads [6595-147]

B. Dong, Q. Zhao, J. Lv, T. Guo, L. Xue, S. Li, H. Gu, Institute of Modern Optics, Nankai Univ. (China)

65954J Three-dimensional vision inspection based on structured light projection and neurocalibration [6595-162]

K. Xie, W. Y. Liu, Z.-B. Pu, Harbin Institute of Technology (China)

65954K Development of fibre optical sensors for structural health monitoring [6595-163]

S. C. Por, L. J. Ping, CPG Labs. Pte Ltd. (Singapore)

Author Index 


\title{
Conference Committees
}

\author{
Conference Chair
}

Jinping Ou, Harbin Institute of Technology (China) and Dalian University of Technology (China)

Conference Cochairs

Yuri N. Kulchin, Far Eastern Branch of the Russian Academy of Sciences (Russia)

Toshihiro Shimizu, Kokushikan University (Japan)

Jae Hun Han, Kangham University (South Korea)

\section{Conference Coordinators}

Zhi Zhou, Harbin Institute of Technology (China)

Oleg B. Vitrik, Far Eastern Branch of the Russian Academy of Sciences

(Russia)

International Scientific Committee

Chair

O. N. Krokhin, Physics Institute of the Russian Academy of Sciences

(Russia)

Cochairs

Yuri N. Kulchin, Far Eastern Branch of the Russian Academy of Sciences

(Russia)

Xiaoyi Bao, University of Ottawa (Canada)

Chunfei Li, Harbin Institute of Technology (China)

Hong Zhao, Harbin University of Science and Technology (China)

V. I. Konov, Russian Foundation for Basic Research, (Russia)

Alexander N. Malov, Irkutsk State University (Russia)

Alen Kost, University of Arizona (USA)

S. M. Shandarov, State University of Control Systems and Radioelectronics (Russia)

E. I. Akopov, SPIE Russia Chapter (Russia)

Qiming Wang, Chinese Academy of Science (China)

F. Ansari, University of Illinois at Chicago (USA)

Jinping Ou, Harbin Institute of Technology (China) and Dalian University of Technology (China)

Xiudong Sun, Harbin Institute of Technology (China)

Yingbao Liao, Tsinghua University (China) 
Toshihiro Shimizu, Kokushikan University (Japan)

Sato Heihachi, National Defense Academy (Japan)

I. Yamaguchi, Gunma University (Japan)

K. Tanaka, Canon Inc. (Japan)

S. Tanaka, National Defense Academy (Japan)

Jae Hun Han, Kangham University (South Korea) 


\section{Introduction}

Global introduction of automated control systems into industry and the everincreasing expansion of fundamental and applied scientific research horizons require various measuring devices that are suitable for real-time monitoring of physical fields, objects, and processes and are capable of being effectively integrated into sophisticated information and measuring systems (IMS). This dictates the need for new approaches to both the organization of the measurement process, and to devising of advanced high-speed IMS, as well as creating new technologies for the design and manufacture of measuring equipment having the ability to endow IMS with such fundamental properties as adaptivity, integration, self-verification, and self-correction capacities.

Modern measuring techniques and devices make wide use of optical, electric, magnetodynamic, piezoelectric, and other sensors. Recent progress in the fiber optic communication technology, both in Russia and abroad, gave birth to a fundamentally new metrology realm: fiber optic sensors (FOS). These sensors are highly advantageous when compared to conventional measuring techniques. The merits of these sensors include high sensitivity and operation speed; electromagnetic noise immunity; small size and weight; combination of measuring and communication function in a single element. There is also great potential of coupling with modern communication and computer systems to create essential prerequisites for the development of radically new distributed and branched multifunction information and measuring systems.

One of the most successful and promising application areas of fiber optic sensors is the measurement of deformation parameters where FOS have already enabled quite a few advanced and currently commercially available systems for structural health monitoring (SHM) of buildings, bridges, high-rise towers, ships, airand spacecrafts. The rapid advancement of FOS in the field of structural health monitoring stems from the progress in a diversity of scientific areas concerned with opto and microelectronics. Among them the following are particularly worthy of note: investigations on new high-efficiency (including non-liner optical) schemes of fiber-guided light modulation by measured physical field parameters, researches on new methods of optical signal processing, exploration of novel micro- and nano-electronic structures for optoelectronics, development of new types of optical fiber sensors and further extending their application potential. The most recent results in the above mentioned fields have become the central focus of attention at the APCOM 2006 conference. 
We would like to express our sincere gratitude to the organizers and sponsors of the conference as well as to all the participants.

Yuri N. Kulchin

Oleg B.Vitrik

Jinping Ou

Zhi Zhou 